\title{
A Influência das Emoções sobre o Efeito Dotação
}

\author{
Flávia Cavazotte* \\ Paulo Dias Filho** \\ Otacílio Vilas Boas***
}

\section{Resumo}

Segundo a teoria prospectiva, indivíduos com aversão à perda tenderiam a atribuir um valor mais elevado a um bem a partir do momento em que a sua propriedade do mesmo estivesse estabelecida. Esta tendência causaria relutância em se desfazer do bem, mesmo que fosse oferecido outro de valor equivalente. Thaler (1980) denominou este fenômeno de efeito dotação. Este artigo apresenta uma revisão da literatura sobre o tema, objeto de intensas pesquisas no campo relativamente recente das finanças comportamentais. Adotando o modelo de pesquisa de Knetsch (1989), dois experimentos foram realizados para investigar o fenômeno em uma amostra brasileira, testando particularmente a influência de emoções positivas e negativas sobre sua manifestação. Os resultados corroboram a ocorrência do efeito dotação, e sugerem que ele é atenuado por emoções negativas. Emoções positivas, no entanto, não tiveram influência perceptível sobre o fenômeno.

Palavras-chave: finanças comportamentais; efeito dotação; emoções.

Códigos JEL: D01; D81; G11.

\section{Abstract}

According to prospect theory, individuals with loss aversion would tend to attribute a higher value to a good once their ownership over it had been established. Such tendency would cause reluctance to trade the good, even if an equivalent one were offered in exchange. Thaler (1980) named this phenomenon endowment effect. In this article, we present a review of the literature about the topic, which has been one of the most investigated themes in the relatively recent field of behavioral finance. Adopting Knetsch's research model (1989), we conducted two experiments in order to investigate the phenomenon in a Brazilian sample, specifically testing the influence of emotions on its manifestation. The results replicate findings for the endowment effect, and suggest that negative emotions attenuate the observed effects. Positive emotions, however, did not have any detectable influence over the phenomenon.

Keywords: behavioral finance; endowment effect; emotions.

Submetido em Setembro de 2008. Aceito em Abril de 2009. O artigo foi avaliado segundo o processo de duplo anonimato além se de ser avaliado pelo editor. Editores responsáveis: Ricardo P. C. Leal e Newton Costa Jr.

* Ibmec/RJ. E-mail: fcavazotte@ibmecrj.br

**Ibmec/RJ. E-mail: paulo_tavares@ hotmail.com

***Ibmec/RJ. E-mail: otaciliotorres@hotmail.com 


\section{Introdução}

Edificado pela fusão da psicologia cognitiva com a teoria econômica, o campo das finanças comportamentais se fundamenta em uma visão alternativa da racionalidade humana para modelar o comportamento dos indivíduos nos mercados, sejam eles de bens ou serviços ou de capitais. Diversos conceitos têm sido propostos pelos teóricos das finanças comportamentais para explicar tendências observadas no comportamento dos agentes, a exemplo do efeito dotação. Descrito de maneira sucinta, o efeito dotação pode ser entendido como o valor adicional que os indivíduos atribuem a bens que eles já possuem. A manifestação desse fenômeno se dá através da disparidade observada entre o valor mínimo da disposição para aceitar pagamento (VDA) por bens e o valor máximo da disposição para pagar (VDP) pelos mesmos.

Há uma série de implicações práticas do efeito dotação. Na área de finanças, ele está relacionado à tendência dos investidores de evitar a realização de perdas em investimentos deficitários, e com o costume dos investidores descreverem perdas em ações como temporárias. Além disso, o estudo do fenômeno também encontra aplicações em áreas como marketing, dado que está associado à prática de apregoar preços como descontos para conquistar consumidores, negociação e solução de conflitos, uma vez que concessões a outros podem ser consideradas como perdas, e políticas ambientais, que podem parecer mais aceitáveis se forem vistas como medidas que mitiguem perdas (Knetsch, 1990).

O objetivo deste artigo é contribuir para a compreensão do efeito dotação, identificando possíveis moderadores do fenômeno, ou seja, fatores que acentuam ou inibem a relutância dos indivíduos em transacionar bens por eles apropriados. A provável influência de processos emocionais na ocorrência do efeito dotação foi sugerida por alguns pesquisadores como uma área potencial de investigação $(\mathrm{Ci}-$ arrochi e Forgas, 2000, Loewenstein e Issacharoff, 1994). A partir da literatura sobre emoções e processos cognitivos (e.g., Forgas (1995), Kunda (1999), Schwarz e Clore (1996)), e particularmente sobre emoção e cognição em processos de tomada de decisão (e.g., Bechara e Damasio (2005), Camerer et alii (2005), Lyubomirsky (2001)), este artigo desenvolve hipóteses sobre o papel de estados afetivos na manifestação do efeito dotação, e apresenta os resultados de experimentos que seguiram o modelo adotado por Knetsch (1989) para analisar o comportamento de agentes quando sob a influência de emoções positivas e negativas.

Após esta introdução, o artigo traz uma revisão da literatura sobre o efeito dotação e sobre o papel das emoções em processos de tomada de decisão, apresentando as premissas teóricas que fundamentam as hipóteses investigadas. Em seguida, a metodologia adotada é descrita e os resultados obtidos são relatados. Por fim, os achados do estudo são discutidos e suas limitações apontadas na conclusão, que inclui também sugestões para pesquisas futuras. 


\section{Revisão de Literatura}

\subsection{O efeito dotação}

O efeito dotação foi originalmente proposto por Thaler em 1980, mas os fundamentos para a compreensão do mesmo foram descritos anteriormente por Kahneman e Tversky (1979) como parte da teoria prospectiva, concorrente à teoria da utilidade esperada ou paradigma racional até então dominante na teoria econômica. Enquanto na teoria econômica clássica o agente seria um indivíduo racional, capaz de realizar cálculos complexos mentalmente, conhecedor de todas as informações relevantes para a tomada de qualquer decisão de forma ótima e desprovida de emoções ou erros de percepção, na teoria prospectiva o agente econômico médio é descrito como um sujeito avesso a riscos, propenso a erros cognitivos decorrentes da forma como a realidade lhe é apresentada, incapaz de calcular corretamente as probabilidades de eventos, e predisposto a se basear muito mais na sua intuição e em determinadas regras gerais para se decidir, geralmente sem o conhecimento perfeito da situação.

Thaler (1980), em um artigo que hoje é considerado uma extensão da teoria prospectiva, utilizou os fundamentos da nova teoria para justificar algumas ilusões mentais identificadas no comportamento dos agentes. Uma dessas ilusões mentais foi observada através de respostas a questões hipotéticas envolvendo custos de oportunidade. O ponto de partida da análise de Thaler foi distinguir entre custos de oportunidade e custos efetivos, uma distinção que não existe na teoria econômica. Utilizando-se da forma da função de valor subjetivo da teoria prospectiva, que possui uma inclinação mais acentuada na região das perdas, e imaginando os custos efetivos como perdas e os custos de oportunidade como ganhos não realizados, o autor concluiu que os primeiros teriam maior peso na avaliação subjetiva de utilidade da teoria prospectiva. A correspondente subavaliação dos custos de oportunidade gerada por esse raciocínio foi denominada por Thaler de endowment effect.

A raiz linguística da palavra "endow" está na palavra latina "dotare", que na língua portuguesa deu origem à palavra "dotar". No caso do fenômeno em estudo, a teoria sugere que um bem é dotado de um maior valor a partir do momento em que sua propriedade é estabelecida. Desse modo, no presente artigo, a expressão "endowment effect" foi traduzida como efeito dotação.

Indivíduos com aversão à perda tenderiam a atribuir um valor mais elevado a um bem, a partir do momento em que a sua propriedade do mesmo estivesse estabelecida. Esse maior valor atribuído ao bem implicaria uma relutância em se desfazer dele, mesmo que lhes fosse oferecido um bem de valor equivalente (Thaler, 1980). 
O efeito dotação foi posteriormente apregoado por Kahneman et alii (1991) como a explicação para a significativa e sistemática divergência, normalmente encontrada em experimentos, entre o VDA e o VDP. A simples existência dessa divergência é, sem dúvida, surpreendente para a maioria dos economistas, pois de acordo com a teoria econômica tradicional, uma vez que efeitos derivados da renda são eliminados, as diferenças entre as duas medidas deveriam ser mínimas.

Para entender a influência do efeito dotação sobre as transações, é preciso partir da hipótese de que as vendas são encaradas como perdas e as compras como ganhos. Se assim for feito, e dada a assimetria entre ganhos e perdas descrita pela teoria prospectiva, as vendas potenciais receberão avaliações geralmente superiores às compras potenciais. Como consequência, o valor mínimo da disposição dos agentes econômicos para aceitar pagamentos em troca dos bens que possuem (VDA) será superior ao valor máximo da disposição dos mesmos para pagar por bens que desejam adquirir (VDP).

A aversão à perda e, consequentemente, o efeito dotação, não afetam todas as transações. Em uma transação comercial normal, o vendedor não sofre uma perda quando negocia um bem. A aversão à perda afeta principalmente os detentores de bens que os adquiriram para uso próprio, em vez de objetivarem uma posterior revenda (Kahneman et alii, 1991).

O efeito dotação, além de servir como justificativa para a divergência entre os valores de VDA e VDP, também implica um volume de transações abaixo do que seria esperado pela análise econômica convencional. Prevê-se pela mesma que, em um mercado com $2 N$ indivíduos e $N$ bens disponíveis, cujos valores não sejam afetados pela posse dos mesmos, o volume de bens espontaneamente transacionados $(V *)$ seja igual a $N / 2$. Se, ao contrário, o efeito dotação está presente, o valor do bem será maior para os vendedores do que para os compradores e, consequentemente, o volume real $(V)$ será menor do que o esperado $(V *)$. A razão $V / V *$ fornece, portanto, um índice relativo do decréscimo do volume de bens negociados devido ao efeito dotação sobre o valor dos bens (Kahneman et alii, 1991). A razão entre o VDA e o VDP, conjuntamente com a razão entre o volume de negócios realizado $(V)$ e o esperado $(V *)$, constituem-se nos dois testes cruciais para a aferição da existência do efeito dotação através de experimentos.

O grau de comparabilidade entre os bens que estão sendo trocados nos experimentos influencia o grau de aversão à perda e, consequentemente, o efeito dotação. Quanto menos comparáveis os bens, menor será a comparabilidade do sentimento de ganho ou perda, ou do valor subjetivo, envolvido na aquisição ou na entrega de um bem. Como produto da falta de comparabilidade, os resultados da troca não poderão ser computados de forma líquida, mas sim calculando em separado o valor subjetivo da aquisição (ganho) e da entrega de um bem (perda). Isso, naturalmente, contribuirá para realçar a perda, dada a assimetria entre ganhos e perdas já mencionada anteriormente (Dijk e Knippenberg, 1998).

Resultados obtidos nos experimentos de Chapman (1998) indicaram que a relutância em realizar uma transação é causada pela aversão à perda e mitigada pela 
similaridade entre os bens, o que lhe permite afirmar que a aversão à perda é em parte determinada pela relação entre os dois bens sendo transacionados. Esse resultado está em consonância com a visão que vincula a aversão à perda às características da transação (trade-loss aversion).

Bello et alii (2003) realizaram experimentos baseados nos estudos de Knetsch (1989) e de Kahneman et alii (1990) na população brasileira, com resultados similares aos observados nas pesquisas internacionais sobre o efeito dotação. Já Decourt e Accorsi (2005), que investigaram o fenômeno através de simulações de investimento com amostras de estudantes de MBA e médicos, apenas verificaram o efeito no último grupo.

Buscando um entendimento mais completo do fenômeno, alguns pesquisadores têm se dedicado à investigação de condições que favoreçam ou atenuem o efeito dotação. Um dos possíveis moderadores discutidos seria o nível de experiência de mercado por parte dos agentes econômicos, mas os resultados das pesquisas são controversos. Coursey et alii (1987) e Shogren et alii (1994), além de outros pesquisadores, utilizaram o recurso da repetição nos experimentos, de forma a simular o acúmulo de experiência. Nos resultados obtidos por estes autores, as medidas de VDA e VDP convergiram à medida que os testes avançaram, o que sugere que a experiência poderia levar à eliminação do efeito dotação. Kahneman et alii (1990) e Morrison (1997), no entanto, não encontraram vinculação entre o grau de experiência e a manifestação do efeito dotação.

De modo a simular grandes variações de experiência de mercado entre os agentes econômicos, Harbaugh et alii (2001) realizaram experimentos envolvendo três grupos diferentes, compostos respectivamente de crianças com idade média de 5 e 10 anos, e de universitários, com idade média de 20 anos. A significativa diferença de idade e maturidade entre os três grupos serviu como um substituto para a experiência acumulada. A comparação entre os resultados obtidos pelos grupos não revelou evidências de que o efeito dotação decresceria com o avançar da idade e, por consequência, com o grau de experiência.

Outro possível moderador do efeito dotação discutido na literatura seria a presença e a ausência de um preço de referência. Experimentos realizados por Lin et alii (2006) examinaram a questão, e seus resultados evidenciaram que o efeito dotação parece ser minimizado quando há um preço de referência. Alguns autores também investigaram efeitos da dependência na origem (source dependence) sobre o efeito dotação. A dependência na origem está associada a diferenças em atribuições de valor feitas pelos indivíduos a respeito de um objeto em função da origem de sua posse. Loewenstein e Issacharoff (1994) verificaram que objetos recebidos como premiação por bom desempenho são em geral percebidos como mais valiosos do que os recebidos por acaso, ou como premiação por desempenho inferior. Em sua pesquisa, estes autores observaram efeitos da dependência na origem de magnitude comparável à do efeito dotação, sugerindo que processos emocionais poderiam afetar julgamentos e outros processos cognitivos. 


\subsection{Emoção e cognição}

Nos últimos vinte anos, pesquisadores têm acumulado evidências de que o processamento de informações e os julgamentos humanos parecem de fato ser afetados por processos emocionais (e.g., Forgas (1995), Kunda (1999), Gollwitzer e Moskowitz (1996)). Os sentimentos resultam de diferentes padrões de atividades neurais e possuem importante papel no controle do comportamento (Panksepp, 2004). As emoções têm como função estimular processos orgânicos e respostas adaptativas ao ambiente, assim como processos de aprendizagem, motivacionais e de comunicação interpessoal, e abarcam qualquer reação afetiva por parte dos indivíduos, como os sentimentos de medo, surpresa, ansiedade, alegria, tristeza ou raiva.

Apesar de haver diversos modelos que descrevem a estrutura das experiências afetivas (cf. Cropanzano et alii (2003)), uma abordagem bastante aceita e investigada empiricamente é o circumplexo afetivo (Watson e Tellegen, 1985, 1999). Neste modelo, as emoções são organizadas em quatro dimensões bipolares: 1) agradabilidade (felicidade/tristeza); 2) afetividade positiva (excitação/lentidão); 3) envolvimento (agitação/quietude); e 4) afetividade negativa (angústia/relaxamento). A partir deste e de outros modelos conceituais, os pesquisadores têm conduzido investigações e reunido evidências fisiológicas, atitudinais e comportamentais que denotam a influência dos afetos sobre os processos mentais, tanto das predisposições de personalidade relativamente estáveis relacionadas às emoções, quanto dos estados de humor transitórios (Forgas, 1995, Kunda, 1999, LeDoux, 2000, Phelps, 2006).

O desenvolvimento da ciência cognitiva permitiu novos avanços na compreensão de mecanismos como a atenção, a percepção, a memória e outros processos mentais. Pesquisas no ramo da neurociência têm contribuído especialmente para um melhor entendimento das interações entre processos emocionais e cognitivos no cérebro. Os processos de tomada de decisão, por exemplo, são notadamente influenciados por diversos sinais marcadores originados em processos biorregulatórios, e estariam sujeitos igualmente aos sinais expressos por emoções e sentimentos em geral (Bechara e Damasio, 2005). Pesquisadores neste campo têm sugerido que a emoção é um elemento importante na interação entre condições ambientais e processos humanos de decisão, pois os sistemas emocionais forneceriam conhecimentos implícitos e explícitos essenciais para escolhas mais rápidas e vantajosas. Sem tais sinais afetivos, as pessoas contariam apenas com uma análise de custos e benefícios com numerosas opções, frequentemente conflitantes.

Em particular, os estudos sobre a fisiologia do cérebro e os mecanismos associados ao medo têm contribuído para explicar as interações entre processos cognitivos e emocionais (LeDoux, 2000). O medo parece ser uma emoção particularmente relevante, por exemplo, em processos de tomada de decisão, e está associado à amígdala, uma área do cérebro que constantemente verifica estímulos aferentes para a indicação de potenciais ameaças, e responde a tais informações tanto em processos involuntários associados ao sistema nervoso autônomo, como naqueles 
intencionalmente controlados no cérebro. Parte do comportamento de aversão ao risco tem sido descrita como resultante da experiência do sentimento de medo e de respostas imediatas a riscos (Camerer et alii, 2005). Alguns autores sugerem que as pessoas vivenciam frequentemente uma discrepância entre o medo relacionado a um risco particular e a avaliação cognitiva da ameaça representada por tal risco (Loewenstein et alii, 2001), sendo comum que reações emocionais a situações de risco divirjam das avaliações cognitivas sobre tais riscos. Quando há divergência, as reações emocionais automáticas, particularmente sensíveis a estímulos como a associação de imagens, frequentemente têm preponderância na condução do comportamento.

Neste artigo nos voltamos particularmente para a afetividade positiva e negativa, e sua influência sobre os processos cognitivos. Parece haver consenso na literatura quanto à tendência a fazermos julgamentos mais favoráveis sobre pessoas e objetos quando tomados por emoções positivas como a alegria e menos favoráveis sob a influência de emoções negativas como a tristeza (Forgas, 1995), quanto ao papel da afetividade como fonte de informação relevante em processos mnemônicos que antecedem as avaliações feitas sobre objetos (Schwarz e Clore, 1996); e quanto à influência dos afetos na escolha de estratégias cognitivas, a negativa favorecendo processamento sistemático e a positiva o processamento heurístico (Isen, 1987). As pesquisas sobre a relevância das emoções para a cognição social e a tomada de decisão dão margem à proposição de que diversos fenômenos no campo das finanças comportamentais, como o efeito dotação, poderiam estar sujeitos à influência dos estados afetivos em sua manifestação.

\subsection{Emoções e o efeito dotação}

Conforme mencionado, uma das relações mais robustas identificadas até hoje na literatura é aquela entre emoções positivas e redução de processamento sistemático de informações, e entre emoções negativas e aumento de processamento sistemático de informações (Chaiken et alii, 1996, Kunda, 1999). Emoções positivas parecem ser mais conducentes à manifestação de vieses heurísticos e ilusões mentais. Emoções negativas, entretanto, motivariam manifestações mais próximas da racionalidade.

O sentimento de alegria seria um indicador de que tudo está bem com relação à realidade ao nosso redor, condição na qual haveria pouca necessidade de uma avaliação mais cuidadosa das circunstâncias ante a uma tomada de uma decisão, o que aumentaria a sujeição do indivíduo à influência dos vieses heurísticos. Alternativamente, um indivíduo em estado depressivo teria maior consciência de suas dificuldades e limitações, e tenderia a raciocinar de forma mais metódica e calculada, o que o resguardaria da influência dos vieses cognitivos (Kunda, 1999). 
Alguns autores também discutem que, no tocante ao comportamento de compra e venda de bens, a vigência de emoções como a tristeza, relacionada aos sentimentos de perda e desesperança, criaria nos indivíduos uma predisposição para engajar em comportamentos motivados pelo desejo de alterar as próprias circunstâncias, e por esta razão estaria associada ao aumento de preços para a compra e redução de preços para a venda de objetos (Lerner et alii, 2004). Se assim for, é de se esperar que o grau do efeito dotação seja mais pronunciado na prevalência de emoções positivas do que de emoções negativas.

$\mathrm{O}$ relacionamento entre o sentimento de felicidade e o comportamento decisório descrito pela teoria prospectiva foi sugerido por Lyubomirsky (2001) como um campo promissor de pesquisa. Evidências levantadas pela pesquisadora demonstram que pessoas caracterizadas como felizes tendem a se sentir satisfeitas com todas as suas decisões e opções, mesmo aquelas que elas não tomaram voluntariamente. Já as pessoas consideradas infelizes geralmente consideram aquilo que elas escolheram ou receberam como medíocres. Seguindo esse raciocínio, se os bens adquiridos forem entendidos como decisões já tomadas, o sentimento de felicidade ou infelicidade dos detentores dos bens deveria ter alguma influência sobre a manifestação do efeito dotação. Assim, o efeito seria mais acentuado entre pessoas consideradas felizes, ou na prevalência da afetividade positiva.

Ciarrochi e Forgas (2000) realizaram um teste para avaliar a influência da suscetibilidade para sentimentos (openness to feelings) e do humor (mood) nas avaliações de valor subjetivo e objetivo dos consumidores. A suscetibilidade para sentimentos funcionou como uma variável representativa da personalidade, mensurando a maior ou menor vulnerabilidade do indivíduo às influências de suas emoções. O humor sintetizaria os estados emocionais transitórios de felicidade e tristeza.

Inicialmente, os participantes listaram bens de consumo que possuíam e que gostariam de adquirir, agrupados por faixa de preço. Depois de submetidos a procedimentos de manipulação de humor na forma de vídeos ou relatos autobiográficos, os participantes foram instados a fornecer os valores subjetivos (VDA para bens possuídos e VDP para potenciais) e objetivos (valor de mercado de bens possuídos e potenciais) desses bens. Através de uma análise de regressão múltipla, foi observada a influência da suscetibilidade para sentimentos, do humor, do status de propriedade (real ou potencial) e do tipo de avaliação (subjetiva ou objetiva), sobre as avaliações subjetivas e objetivas fornecidas sobre os bens (Ciarrochi e Forgas, 2000).

A interação entre suscetibilidade para sentimentos e humor não foi significativa em relação às avaliações objetivas. Já em relação às avaliações subjetivas, o experimento revelou que a suscetibilidade para sentimentos modera o efeito do humor sobre avaliações de bens de consumo. Indivíduos com alta suscetibilidade para sentimentos costumam adotar avaliações consistentes com seus humores como, por exemplo, avaliações subjetivas positivas quando bem humorados. Já indivíduos com baixa suscetibilidade para sentimentos experimentam uma reversão 
dos efeitos de seus humores, respondendo, por exemplo, com avaliações subjetivas negativas quando bem humorados. Esses resultados parecem ser bastante robustos, pois são comuns a diferentes condições utilizadas no experimento, como método de indução do humor usado e faixas de preço dos bens avaliados (Ciarrochi e Forgas, 2000).

As observações sobre as avaliações subjetivas no estudo de Ciarrochi e Forgas (2000) foram estendidas pelos autores ao efeito dotação, embora sem muita convicção, já que esse não foi um dos objetivos do experimento, e nem a metodologia era a mais apropriada para a medição do fenômeno. Porém, Lerner et alii (2004) observaram efeitos significativos da tristeza e da repugnância nas decisões dos agentes sobre preços de compra e venda, que seriam reversivos do efeito dotação. A relação entre afetividade positiva e negativa e o efeito dotação também foi alvo de um estudo conduzido por Lin et alii (2006), indicativo de que ele seria observado quando emoções positivas são induzidas nas pessoas, mas desapareceria no caso de indução a emoções negativas.

\section{Hipóteses}

Este estudo testou três hipóteses relativas ao efeito dotação.

- Hipótese 1: o efeito dotação é observado na população estudada.

- Hipótese 2: estados emocionais positivos tornam os agentes mais propensos a manifestar o efeito dotação.

- Hipótese 3: estados emocionais negativos tornam os agentes menos propensos a manifestar o efeito dotação.

\section{Metodologia}

Para testar as hipóteses propostas, foram realizados dois experimentos laboratoriais numa amostra de alunos de cursos de MBA e Mestrado em Administração de uma instituição de ensino do Rio de Janeiro, no segundo semestre de 2004. Todos os participantes dos experimentos tinham no mínimo nível de instrução superior completo, $65 \%$ eram do sexo masculino e $80 \%$ declararam ter renda superior a 20 salários mínimos. As idades variaram de 23 a 60 anos, sendo a idade média 33.0 e o desvio padrão 8.2. O tempo médio de experiência profissional declarado foi de 12.5 anos, sendo o desvio padrão 8.1. Em relação às experiências dos participantes como investidores, $49 \%$ disseram ter pouca ou nenhuma experiência, $30 \%$ disseram ter alguma experiência e $21 \%$ disseram ter muita experiência. O primeiro experimento testou a hipótese 1 e o segundo experimento testou as hipóteses 2 e 3. 
Precedendo os experimentos conduzidos no âmbito deste artigo, foi realizado um teste piloto com um grupo de 53 estudantes, de modo a aferir e confirmar a equivalência de preferências pelos dois bens utilizados neste estudo (barras de chocolate de $30 \mathrm{~g}$ dos tipos A e B). Esperava-se que nesse grupo houvesse uma proporção próxima a $50 \%$ de preferência por cada um dos bens. Algum resultado muito distante desse patamar inviabilizaria a asserção da existência do efeito dotação durante os experimentos subsequentes.

Seguindo a metodologia de Knetsch (1989), o primeiro experimento envolveu um grupo de 32 estudantes, que foi denominado de grupo I. Estes indivíduos receberam uma barra de chocolate de $30 \mathrm{~g}$ do tipo A como compensação pelo preenchimento de um questionário. Os estudantes foram comunicados de que poderiam manter o bem entregue, assim como qualquer outro que lhes viesse a ser entregue durante o experimento. Em seguida, já de posse do bem e após o manuseio do mesmo, lhes foi solicitado que preenchessem o questionário, com perguntas sobre o perfil demográfico do participante. Após o preenchimento e devolução do questionário, foi oferecida a possibilidade de trocar o bem recebido por uma barra de chocolate de $30 \mathrm{~g}$ do tipo B, exibida então aos participantes, e as trocas solicitadas foram efetuadas.

Tabela 1

Primeiro experimento

\begin{tabular}{ccc}
\hline Grupo & Hipótese testada & Procedimento \\
\hline I & O efeito dotação é observado & $\begin{array}{c}\text { Chocolate tipo } \mathrm{A} \rightarrow \text { Oferta de troca } \\
\text { por chocolate tipo B }\end{array}$ \\
\hline
\end{tabular}

De acordo com os pressupostos da teoria prospectiva e com os resultados dos experimentos já realizados por Knetsch (1989) e por outros autores, se esperaria uma significativa relutância por parte dos estudantes do grupo I em realizar a troca proposta. O maior valor atribuído ao bem já apropriado pelo indivíduo, como preconiza o efeito dotação, seria a explicação para que um percentual menor do que $50 \%$ dos participantes aceitasse a substituição do bem inicial por outro equivalente.

O segundo experimento seguiu procedimentos idênticos ao primeiro, porém nele foi introduzida uma modificação importante, com o intuito de apurar a possível influência das emoções sobre a manifestação do efeito dotação: a manipulação de estados emocionais. O mecanismo utilizado para manipular os estados emocionais dos participantes foi a exibição de vídeos no experimento. Um dos vídeos apresentava trechos do filme "De Volta para o Futuro", uma consagrada comédia americana, para induzir emoções positivas nos participantes. O outro vídeo apresentava trechos do filme "A Última Ceia", com cenas que antecedem a execução de um prisioneiro condenado à morte, para induzir emoções negativas nos participantes.

O respaldo teórico para a utilização de vídeos na indução de emoções pode ser encontrado, por exemplo, no artigo de Bushman (1998), que pesquisou a influência de cenas de violência exibidas em vídeos sobre as emoções dos parti- 
cipantes dos experimentos que conduziu. Segundo o autor, cenas de violência exibidas na mídia imprimem construtos agressivos na memória, tornando-os mais acessíveis aos telespectadores. Esperava-se observar, em relação aos participantes deste experimento, um processo de assimilação de imagens semelhante, que os levaria a estados emocionais correlatos ao conteúdo dos filmes (Bushman, 1998).

O experimento foi então realizado com dois grupos de 34 alunos cada, denominados grupos II e III. O grupo II foi submetido ao vídeo conducente de emoções positivas e o grupo III ao de emoções negativas. De modo similar ao primeiro experimento, os participantes dos dois grupos receberam, inicialmente, uma barra de chocolate do tipo A. Após a entrega da barra de chocolate, teve início a exibição do respectivo vídeo a cada grupo, por um período de aproximadamente 15 minutos. Em seguida, foi solicitado o preenchimento do mesmo questionário utilizado no primeiro experimento. Finalizando o procedimento, foi feita uma oferta de troca da barra de chocolate recebida inicialmente por outra do tipo B, exibida então aos participantes, e as trocas solicitadas foram efetuadas. Um cuidado importante neste experimento foi que cada vídeo somente fosse exibido após a entrega do primeiro bem aos participantes, e antes do preenchimento do questionário e da oferta de troca pelo outro bem. A intenção era que o efeito da indução de afetividade se realizasse integralmente após a posse do bem inicial, e fosse sustentado sem maiores intervenções até que a opção de troca fosse apresentada.

Tabela 2

Segundo experimento

\begin{tabular}{ccc}
\hline Grupo & Hipótese testada & Procedimento \\
\hline II & $\begin{array}{c}\text { Estados emocionais positivos } \\
\text { tornam os agentes mais propensos } \\
\text { a manifestar o efeito dotação }\end{array}$ & $\begin{array}{c}\text { Chocolate tipo } \mathrm{A} \rightarrow \text { Cenas alegres } \rightarrow \\
\text { Oferta de troca por chocolate tipo B }\end{array}$ \\
\hline III & $\begin{array}{c}\text { Estados emocionais negativos } \\
\text { tornam os agentes menos propensos } \\
\text { a manifestar o efeito dotação }\end{array}$ & $\begin{array}{c}\text { Chocolate tipo } \mathrm{A} \rightarrow \text { Cenas tristes } \rightarrow \\
\text { Oferta de troca por chocolate tipo B }\end{array}$ \\
\hline
\end{tabular}

\section{Resultados}

No primeiro experimento, foi aplicado um teste de proporção, comparando o percentual real de trocas observadas contra $50 \%$, buscando estabelecer se a proporção encontrada era significativamente menor do que o valor esperado (\% trocas grupo $I<50 \%)$. Apenas 4 participantes $(12.5 \%$ do total de 32 participantes) aceitaram a oferta de troca. O resultado obtido no teste, a um nível de significância de $1 \%(z=-4.24, p<0.01)$, permitiu rejeitar a hipótese nula e aceitar a hipótese alternativa (Kazmier, 1982), confirmando o efeito dotação no grupo I e validando a hipótese 1.

No segundo experimento, a fim de verificar estatisticamente os efeitos da manipulação de estados emocionais induzida pelos vídeos, foi utilizada a análise da variância (ANOVA), comparando os estados emocionais dos indivíduos nos grupos que sofreram a intervenção (II e III) com aqueles que participaram no grupo 
I, no qual não houve manipulação dos estados afetivos dos participantes (grupo de controle). O resultado indicou que houve uma diferença significativa entre os grupos nessa variável $\left[F_{(3,134)}=3.966, p<0.01\right]$, sugerindo ter sido alcançado o efeito de manipulação das emoções intencionado com o uso dos filmes.

E de fato, segundo os dados obtidos através do inventário aplicado, a afetividade transitória dos participantes do grupo III, submetidos a cenas indutivas de emoções negativas, foi estatisticamente distinta da afetividade do grupo I. A média do grupo III foi inferior à do grupo I $\left(\overline{\mathbf{X}}_{\text {grupo III }}=4.563 ; \overline{\mathbf{X}}_{\text {grupo I }}=5.175\right)$, dando suporte ao efeito da manipulação de estados emocionais negativos naquele grupo.

Entretanto, o efeito pretendido de indução de emoções positivas não foi observado no grupo II. As médias dos índices dos grupos I e II foram praticamente idênticas $\left(\overline{\mathbf{X}}_{\text {grupo I }}=5.175 ; \overline{\mathbf{X}}_{\text {grupo II }}=5.171\right)$. Esse resultado sugere que a manipulação através das cenas da comédia não surtiu o efeito desejado.

Dos 34 participantes do grupo II, 8 se dispuseram a realizar a troca $(23.5 \%)$. A rigor, não haveria porque ir em frente e testar a hipótese 2 , uma vez que não houve distinções na variável independente (estados afetivos) entre este e o grupo I. Mesmo assim, vale ressaltar que a proporção de trocas no grupo II não foi significativamente diferente daquela observada no grupo I $(z=1.94, n s)$, o que parece consistente com os resultados do efeito da manipulação, que apresentaram níveis semelhantes de afetividade, e rende evidências mais uma vez da manifestação do efeito dotação previamente observada no grupo I.

No grupo III, 9 dos 34 participantes se dispuseram a realizar a troca $(26.5 \%)$. O resultado do teste de proporção $(z=2.46, p<0.01)$ permitiu rejeitar a hipótese nula (Kazmier, 1982), oferecendo evidências de que houve um percentual de trocas maior do que no grupo I. Em outras palavras, a hipótese 3 foi confirmada.

Tabela 3

Resultados

\begin{tabular}{l|c|c|c}
\hline \multicolumn{1}{c|}{ Informações } & Grupo I & Grupo II & Grupo III \\
\hline Participantes & 32 & 34 & 34 \\
\hline Proporção de trocas $(p t)$ & $12.5 \%$ & $23.5 \%$ & $26.5 \%$ \\
\hline Parâmetro para comparação & $50.0 \%$ & $12.5 \%$ & $12.5 \%$ \\
\hline Hipótese nula $\left(H_{0}\right)$ & $p t \geq 0.50$ & $p t \geq 0.125$ & $p t \leq 0.125$ \\
\hline Hipótese alternativa $\left(H_{1}\right)$ & $p t<0.50$ & $p t<0.125$ & $p t>0.125$ \\
\hline Erro padrão da proporção & 0.09 & 0.06 & 0.06 \\
\hline$z$ estatístico & -4.24 & 1.94 & 2.46 \\
\hline$z$ crítico $(\alpha=0.01)$ & -2.33 & -2.33 & 2.33 \\
\hline$z$ crítico $(\alpha=0.05)$ & -1.65 & -1.65 & 1.65 \\
\hline Resultado $(\alpha=0.01)$ & $H_{0}$ rejeitada & $H_{0}$ não rejeitada & $H_{0}$ rejeitada \\
\hline Resultado $(\alpha=0.05)$ & $H_{0}$ rejeitada & $H_{0}$ não rejeitada & $H_{0}$ rejeitada \\
\hline \multicolumn{3}{|l}{}
\end{tabular}




\section{Discussão}

Os resultados obtidos no primeiro experimento rendem evidências de que haveria uma acentuada relutância em realizar trocas envolvendo bens apropriados pela amostra do estudo, corroborando os achados de Knetsch (1989) e de outros pesquisadores que investigaram a ocorrência do efeito dotação (e.g., Bello et alii (2003), Morrison (1997)), e ampliando a validade externa da teoria sobre o efeito na população estudada. Sobretudo, o primeiro experimento estabelece a base fundamentalmente necessária para justificar as análises subsequentes no contexto desta pesquisa, que têm como premissa a tendência ao efeito dotação.

O segundo experimento diz respeito à verificação da influência moderadora da afetividade positiva e negativa sobre o efeito dotação. Neste estudo, foi observado que a indução de emoções negativas no grupo III não somente parece ter sido eficaz, como está associada de forma significativa ao percentual de trocas em relação ao grupo no qual não houve manipulação, indicando que estados afetivos negativos atenuariam o efeito. Esta observação respalda a proposição de Olsen (2001) de que os tomadores de decisão tenderiam a incorporar a emoção em processos de decisão. Ela também está alinhada com as inferências de estudos da psicologia cognitiva sobre a afetividade negativa como fator redutor de vieses de julgamento e promotor de um processamento mais sistemático de informações (Chaiken et alii, 1996, Isen, 1987, Kunda, 1999), e com as observações de outros autores sobre a relação entre afetividade negativa e o efeito dotação (Lerner et alii, 2004, Lin et alii, 2006).

Contudo, a hipótese de que estados emocionais positivos tornariam os agentes mais propensos a manifestar o efeito dotação não pôde ser verificada. No segundo experimento, a indução de emoções positivas no grupo II não atingiu o efeito desejado, impedindo qualquer afirmação definitiva em relação à influência desses estados emocionais sobre o efeito dotação (cf. Cook e Campbell (1979)). Aparentemente, a manipulação de emoções através de vídeos, bem sucedida no caso de emoções negativas, não surtiu o mesmo efeito no caso das emoções positivas. $\mathrm{O}$ filme "De Volta para o Futuro", do qual se extraiu o trecho utilizado para induzir emoções positivas, pode não ter constituído um tratamento experimental suficientemente forte para induzir afetividade positiva em níveis elevados na população estudada. Embora os filmes sejam frequentemente usados para manipular emoções negativas como a tristeza e a repugnância (Lerner et alii, 2004), é possível também que o efeito deste tipo de estratégia na manipulação da afetividade positiva não seja tão eficaz quanto as técnicas que utilizam a recordação de eventos agradáveis, a oferta de brindes ou a promoção da experiência de sucesso em jogos experimentais.

Entretanto, apesar desta limitação, não se deve descartar a possibilidade de o efeito dotação ser mais fundamentalmente afetado pela afetividade negativa do que pela positiva. Novos experimentos seriam exigidos para trazer mais confiança a qualquer afirmação a respeito. 


\section{Conclusão}

O componente irracional das decisões, gerado pela intervenção humana, sempre representou um desafio para estrategistas, pensadores, líderes, qualquer um encarregado de decidir ou avaliar o impacto de possíveis alternativas de ação em processos de tomada de decisão. As asserções de Slovic (1972) em seu trabalho seminal sobre as limitações humanas no processamento de informações e decisões financeiras, e a posterior articulação da teoria prospectiva (Kahneman e Tversky, 1979) possibilitaram o debate sobre esse componente nas teorias de finanças, e a expansão do rico campo de pesquisa das finanças comportamentais, domínio ao qual pertence este estudo. A julgar-se pela multiplicação de publicações em anais e periódicos sobre temas como os vieses heurísticos em atribuições de preço e valor (e.g., Serpa e Avila (2004)) e ineficiência dos mercados (e.g., Minardi (2004)), entre outros, parece haver um interesse crescente também na comunidade acadêmica brasileira por este campo de estudos.

Os resultados observados em nossa pesquisa no tocante ao efeito dotação ampliam a universalidade da justificativa proposta por Thaler para a disparidade VDA (valor mínimo da disposição para aceitar pagamento) - VDP (valor máximo da disposição para pagar), talvez um dos pontos centrais do contencioso entre a teoria econômica e as finanças comportamentais (Kahneman et alii, 1990, Thaler, 1980). Porém, a contribuição principal da pesquisa está na investigação empírica da relevância dos estados afetivos para o efeito dotação, e na apresentação de evidências que indicam uma inibição do efeito em face da vigência de estados afetivos negativos.

Esta investigação avança as proposições apregoadas por autores interessados na influência dos afetos sobre o efeito dotação (Ciarrochi e Forgas, 2000, Loewenstein e Issacharoff, 1994), agregando dados adicionais sobre fatores que podem moderar a sua manifestação. Deste modo, também corrobora a descrição de Olsen (2001) da tomada de decisões por agentes econômicos como um processo analógico, intuitivo e dependente da situação, que não pode ser explicado exclusivamente por fatores mecanicistas baseados em regras e por elementos cognitivos, mas que estaria sujeito também à predisposição neurológica dos indivíduos de incorporar emoções em tal processo.

Como sugestões para futuras pesquisas sobre o assunto, podem ser citadas: a) a aplicação do presente formato de experimentos utilizando-se outros tipos de bens ou investigando o papel de outras emoções no efeito dotação; b) o aprimoramento da estratégia de investigação de modo a sanar as limitações metodológicas quanto à eficácia na indução de emoções positivas e possibilitar seu estudo; c) a extensão dos testes a uma amostra maior de agentes segmentados por graus de vivência como investidores, permitindo aferir a relação entre a experiência, afetividade e o efeito dotação; e d) a realização de estudos semelhantes nos quais os grupos de participantes variem de forma sistemática em níveis sócio-econômicos e quanto ao perfil em relação ao risco (conservadores, moderados e agressivos). 
Em suma, este artigo também chama a atenção dos interessados nas finanças comportamentais para a influência de processos emocionais na tomada de decisão, e, contrariando a suposição equívoca da antítese entre emoção e racionalidade, sugere que algumas emoções humanas podem contribuir para um processamento mais racional de informações. No entanto, a despeito da importância dos estados afetivos para as escolhas econômicas diárias dos indivíduos nos mercados, é oportuno e ainda necessário expandir as investigações científicas sobre as diversas manifestações do fenômeno e os diferentes mecanismos que explicam os efeitos observados.

\section{Referências}

Bechara, A. \& Damasio, A. (2005). The somatic marker hypothesis: A neural theory of economic decision. Games and Economic Behavior, 52(2):336-372.

Bello, A., Alves, J. P., \& Avila, M. G. (2003). Julgamento e tomada de decisão: Um estudo experimental do endowment effect no Brasil. Anais do XXVII ENANPAD, Atibaia.

Bushman, B. J. (1998). Priming effects of media violence on the accessibility of aggressive constructs in memory. Personality and Social Psychology Bulletin, 24(5):537-545.

Camerer, C., Loewenstein, G., \& Prelec, D. (2005). Neuroeconomics: How neuroscience can inform economics. Journal of Economic Literature, 43(1):9-64.

Chaiken, S., Wood, W., \& Eagly, A. (1996). Principles of persuasion. In Higgins, A. \& Kruglanski, A., editors, Social Psychology: Handbook of Basic Principles, pages 702-742. Guilford Press, New York.

Chapman, G. B. (1998). Similarity and reluctance to trade. Journal of Behavioural Decision Making, 11(1):47-58.

Ciarrochi, J. \& Forgas, J. P. (2000). The pleasure of possessions: Affective influences and personality in the evaluation of consumer items. European Journal of Social Psychology, 30(5):631-649.

Cook, T. D. \& Campbell, D. T. (1979). Quasi-Experimentation: Design and Analysis Issues for Field Settings. Rand McNally, Chicago.

Coursey, D. L., Hovis, J. L., \& Schulze, W. D. (1987). The disparity between willingness to accept and willingness to pay measures of value. Quarterly Journal of Economics, 102(3):679-690.

Cropanzano, R., Weiss, H., Hale, J., \& Reb, J. (2003). The structure of affect: Reconsidering the relationship between negative and positive affectivity. Journal of Management, 29(6):831-857. 
Decourt, R. \& Accorsi, A. (2005). As finanças comportamentais e o processo de decisão no mercado financeiro brasileiro. Anais do XXIX ENANPAD, Brasília.

Dijk, E. \& Knippenberg, D. (1998). Trading wine: On the endowment effect, loss aversion and the comparability of consumer goods. Journal of Economic Psychology, 19(4):485-495.

Forgas, J. P. (1995). Mood and judgment: The affect infusion model (AIM). Psychological Bulletin, 117(1):39-56.

Gollwitzer, P. M. \& Moskowitz, G. B. (1996). Goal effects on action and cognition. In Higgins, A. \& Kruglanski, A., editors, Social Psychology: Handbook of Basic Principles, pages 361-399. Guilford Press, New York.

Harbaugh, W. T., Krause, K., \& Vesterlund, L. (2001). Are adults better behaved than children? Age experience and the endowment effect. Economics Letters, 70(2):175-181.

Isen, A. M. (1987). Positive affect, cognitive processes, and social behavior. Advances in experimental social psychology, 20:203-253.

Kahneman, D., Knetsch, J. L., \& Thaler, R. H. (1990). Experimental tests of the endowment effect and the coase theorem. Journal of Political Economy, 98(6):1325-1348.

Kahneman, D., Knetsch, J. L., \& Thaler, R. H. (1991). The endowment effect, loss aversion, and status quo bias. Journal of Economic Perspectives, 5(1):193-206.

Kahneman, D. \& Tversky, A. (1979). Prospect theory: An analysis of decision under risk. Econometrica, 47(2):263-291.

Kazmier, L. J. (1982). Estatística Aplicada À Economia e Administração. Editora McGraw-Hill do Brasil, São Paulo.

Knetsch, J. L. (1989). The endowment effect and evidence of nonreversible indifference curves. The American Economic Review, 79(5):1277-1284.

Knetsch, J. L. (1990). Environmental policy implications of disparities between willingness to pay and compensation demanded measures of values. Journal of Environmental Economics and Management, 18(3):227-237.

Kunda, Z. (1999). Social Cognition. MIT Press, Cambridge.

LeDoux, J. E. (2000). Emotion circuits in the brain. Annual Review of Neuroscience, 23:155-184.

Lerner, J. S., Small, D. A., \& Loewenstein, G. (2004). Heart strings and purse strings: Carryover effects of emotions on economic decisions. Psychological Science, 15(5):337-341. 
Lin, C., Chuang, S., Kao, D., \& Kung, C. (2006). The role of emotions in the endowment effect. Journal of Economic Psychology, 27(4):589-597.

Loewenstein, G. \& Issacharoff, S. (1994). Source dependence in the valuation of objects. Journal of Behavioral Decision Making, 7(3):157-168.

Loewenstein, G., Weber, E., Hsee, C., \& Welch, N. (2001). Risk as feelings. Psychological Bulletin, 127(2):267-286.

Lyubomirsky, S. (2001). Why are some people happier than others? The role of cognitive and motivational processes in well-being. American Psychologist, 56(3):239-249.

Minardi, A. M. (2004). Retornos passados prevêem retornos futuros? RAEEletrônica, 3(2).

Morrison, G. C. (1997). Willingness to pay and willingness to accept: Some evidence of an endowment effect. Applied Economics, 29(4):411-417.

Olsen, R. A. (2001). Behavioural finance as science: Implications from the research of Paul Slovic. Journal of Psychology and Financial Markets, 2(3):157159.

Panksepp, J. (2004). Affective Neuroscience: The Foundations of Human and Animal Emotions. Oxford University Press, New York.

Phelps, E. A. (2006). Emotion and cognition: Insights from studies of the human amygdala. Annual Review of Psychology, 57:27-53.

Schwarz, N. \& Clore, G. (1996). Feelings and phenomenal experiences. In Higgins, A. \& Kruglanski, A., editors, Social Psychology: Handbook of Basic Principles, pages 433-465. Guilford Press, New York.

Serpa, D. A. \& Avila, M. G. (2004). Percepção sobre preço e valor: Um teste experimental. RAE-Eletrônica, 3(2).

Shogren, J. F., Shin, S. Y., Hayes, D. J., \& Kliebenstein, J. B. (1994). Resolving differences in willingness to pay and willingness to accept. American Economic Review, 84(1):255-270.

Slovic, P. (1972). Psychological study of human judgment: Implications for investment decision making. Journal of Finance, 27(4):779-799.

Thaler, R. H. (1980). Toward a positive theory of consumer choice. Journal of Economic Behaviour and Organization, 1(1):39-60.

Watson, D. \& Tellegen, A. (1985). Toward a consensual structure of mood. Psychological Bulletin, 98(2):219-235. 
Watson, D. \& Tellegen, A. (1999). Issues in the dimensional structure of affect: Effects of descriptors, measurement error, and response formats: Comment on Russell and Carroll. Psychological Bulletin, 125:601-610. 